\title{
Compensatory growth in $C$. elegans is regulated by a thermosensitive TRP channel and increases reproductive fitness
}

\author{
Zuzana Sekajova ${ }^{1 *}$, Elena Rosa ${ }^{1 *}$, Foteini Spagopoulou ${ }^{1}$, \\ Panagiotis-Ioannis Zervakis ${ }^{1}$ and Martin I. Lind ${ }^{1}$
}

\footnotetext{
${ }^{1}$ Animal Ecology, Department of Ecology and Genetics, Uppsala University, 75236 Uppsala, Sweden

* These authors contributed equally to the study
}

\begin{abstract}
Animals are often not growing at the maximum rate, but can compensate for a bad start of life by further increasing growth rate. While this compensatory growth is widespread, its direct fitness consequences are seldom investigated and its genetic basis is unknown. We investigated the genetic regulation, as well as fitness and lifespan consequences of compensatory growth in response to temperature, using $C$. elegans knockout of the thermo-sensitive TRP ion channel TRPA-1, involved in temperature recognition. We exposed juvenile worms to cold, normal or warm temperatures in order to delay or speed up development. After returning to normal temperature, we found that wild-type worms where early development was delayed, expressed compensatory growth and catched up in size, while juvenile exposure to warm temperatures expressed slowed-down growth and small size. Compensatory growth also altered the reproductive schedule towards early reproduction, so that ratesensitive individual fitness increased even though total reproduction was unaffected. Surprisingly, no lifespan cost of compensatory growth was found. In contrast,
\end{abstract}


juvenile temperature did not induce compensatory or slowed-down growth in the trpa-1 knockout mutants, and consequently did not affect fitness. We show that temperature-induced compensatory growth in C. elegans is regulated by the trpa-1 and can increase fitness. 


\section{Introduction}

Adaptive phenotypic plasticity is the ability of one genotype to alter its phenotype depending upon the environmental conditions, in order to increase performance in a specific environment [1]. One remarkable form of plasticity is compensatory growth $[2,3]$, which is the ability to plastically modify and specifically increase growth rate once environmental conditions return favorable after a bad start in life (typically during early development [2]). Since large adult body size in combination with short development time is often beneficial [4], it is surprising that organisms are rarely found to grow at the maximum rate possible in a given environment [5].

Conversely, a common observation is that organisms faced with poor juvenile conditions (such as low temperature or food availability) are constrained to a low early-life growth rate, which can be increased in later life stages as a plastic response to compensate for the bad start. Importantly, such poor-condition individuals can have higher growth rate and may reach the same size as individuals that were not restricted as juveniles, which is termed compensatory growth [6,7]. Examples of compensatory growth are widespread [7]; it is present in organisms such as mice [8], frogs [9-11], zebra finches [12] and fish such as sticklebacks [13,14], green swordtails [15] and salmon [16]. Typically, compensatory growth is expected to be adaptive in environments with a limited window for development and reproduction, such as timeconstrained environments with strong seasonality [9,17]. Despite an extensive research interest in compensatory growth plasticity, studies mostly focus on growth and associated costs in relation to lifespan [18] and recently adult physiology [10,11]. However, reproductive performance is an essential element for understanding of the life-history consequences of compensatory growth, but is seldom investigated (notable exceptions are [3,19]). Moreover, while we now have an understanding of 
the selective pressures operating on the evolution of compensatory growth plasticity and some costs have been identified, its genetic regulation remains unknown.

Studies in model organisms have identified the evolutionary conserved nutrient-sensing pathways (i.e. insulin/insulin-like growth factor signaling [IIS] and mechanistic target-of-rapamycin [mTOR]) as key regulators of life-history traits such as growth, reproduction and lifespan across animals [20-25]. Importantly, these nutrient-sensing pathways can also underlie adaptive phenotypic plasticity. While IIS/mTOR are well known to respond to nutrient status, they are also key life-history regulators that take input from a range of environmental cues, including photoperiod and temperature [26-28]. For example, insulin signaling and temperature regulate body size plasticity in Hydra [29], and are involved in body size polyphenism in horned beetles [30] and in ovariole number in Drosophila [31]. Therefore, it has recently been proposed that IIS/mTOR have evolved as general and conserved regulators of adaptive phenotypic plasticity [25], since they integrate upstream environmental cue recognition and downstream signaling into a physiological response. Therefore, these pathways and genes could also be part of the proximate mechanisms underlying adaptive compensatory growth.

Two common environmental factors that result in a poor start in life are low food availability [7] and/or low temperature [13]. The latter can be less invasive to study experimentally, as it does not alter the nutritional intake per se $[32,33]$ and, therefore, any observed costs of compensatory growth would not be caused by malnutrition, but by differential growth patterns [13]. Hence, one vital cue with relevance for compensatory growth plasticity is temperature recognition. In the nematode worm Caenorhabditis elegans, the cold-sensitive TRP channel, specifically TRPA-1 (regulated by trpa-1 gene), can detect drop in temperature and regulate 
lifespan by modulating IIS signaling [34]. Furthermore, TRPA-1 acts in an age- and thermal-specific manner by extending lifespan upon adult cold-exposure but reducing it upon larval cold-exposure via signaling to DAF-16 in the IIS pathway, which in turn alters gene expression $[34,35]$. The reduced lifespan under low larval temperature is very intriguing from a compensatory growth perspective, as it is a potential cost of compensatory growth after suboptimal juvenile conditions [13]. In particular, Zhang et al. [35] placed mature C. elegans adults to oviposit at $15^{\circ} \mathrm{C}, 20^{\circ} \mathrm{C}$ and $25^{\circ} \mathrm{C}$ and allowed the resulting offspring to develop in their respective temperature until the last larval instar, after what they were transferred to the optimal temperature of $20^{\circ} \mathrm{C}$. They found that individuals reared at $15^{\circ} \mathrm{C}$ as juveniles lived shorter and did not pay any reproductive costs associated with lifespan variation. Although growth was not measured in Zhang et al. [35], their results are compatible with the model of costly compensatory growth after juvenile exposure to unfavorable conditions, regulated by trpa-1 and the IIS pathway.

We set out to investigate the presence, costs and benefits of compensatory and slowed-down growth, as well as its genetic regulation, using the nematode C. elegans. TRPA-1 is involved in the regulation of plasticity in adult lifespan in response to suboptimal juvenile temperatures in C. elegans via regulation of DAF-16 in the IIS pathway [35]. Hence, we measured compensatory growth plasticity, age-specific reproduction and lifespan in wild-type worms as well as worms with a null-mutation in the trpa-1 gene. We found that wild-type worms express compensatory growth plasticity when returned to optimal conditions after juvenile exposure to low temperatures, which was accompanied by increased fitness, but no lifespan cost over cold-exposed trpa-1 mutants. In contrast, the trpa-1 mutant worms did not express 
compensatory growth plasticity, highlighting the importance of IIS signaling for compensatory growth plasticity.

\section{Methods}

\section{$\underline{\text { Strains }}$}

We used the wild-type strain N2 and the mutant trpa-1(ok999), orthologue of human TRPA-1, which has a role in ion channel activity and is located in the IV chromosome [36].

\section{Experimental design}

Worms were reared on agar plates with NGM medium and antibiotics (streptomycin and kanamycin) and fungicide (nystatin) [37] and seeded with the antibiotic-resistant OP50-1 (pUC4K) Escherichia coli strain. Worms of both strains were revived from freezing, bleached twice and reared at standard laboratory conditions $\left(20^{\circ} \mathrm{C}, 60 \% \mathrm{RH}\right.$ and no light) before the experiment to synchronize generation time and remove infections. We exposed newly laid eggs to one of three temperature treatments (Figure 1), where the larvae would develop until reaching the third larval instar $\left(\mathrm{L}_{3}\right)$, whereafter they were moved to standard temperature $\left(20^{\circ} \mathrm{C}\right)$. The $20^{\circ} \mathrm{C}$ treatment is the normal temperature during standard laboratory conditions, and development to $\mathrm{L}_{3}$ takes $42 \mathrm{~h}$. The $15^{\circ} \mathrm{C}$ treatment delays development substantially, and it takes $72 \mathrm{~h}$ to reach $\mathrm{L}_{3}$. This treatment is designed to induce compensatory growth, if present. Finally, the $25^{\circ} \mathrm{C}$ treatment speeds up development, and $\mathrm{L}_{3}$ is reached after $32 \mathrm{~h}$. The development time to $\mathrm{L}_{3}$ was determined in pilot studies using both strains. The experiment was designed so that worms of all larval temperature treatments would simultaneously reach 


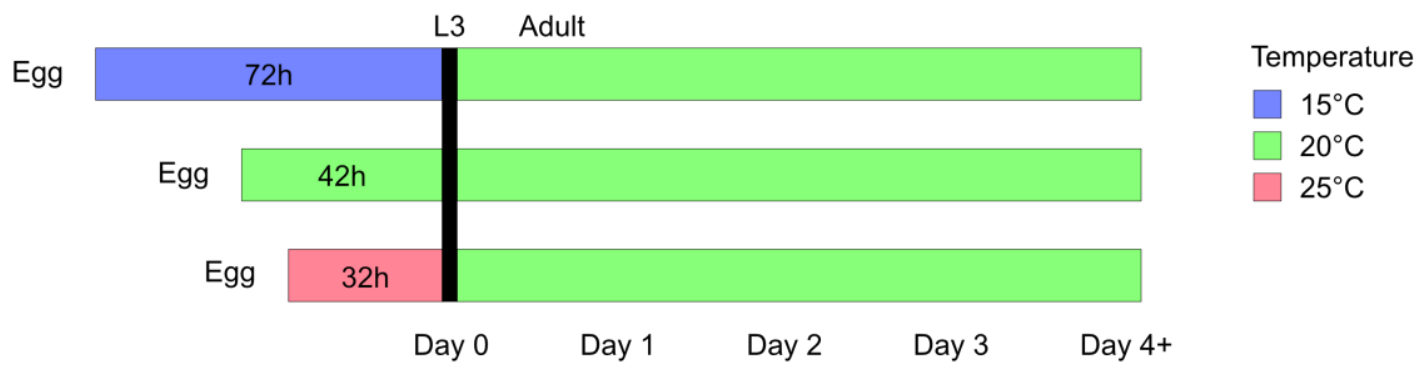

Figure 1. Experimental design. Overview of the experimental design. Eggs from parents reared in $20^{\circ} \mathrm{C}$ were placed into the three temperature treatments, where larvae developed until reaching the $\mathrm{L}_{3}$ larval stage. Thereafter, they were kept in $20^{\circ} \mathrm{C}$ for the remainder of the experiment. Treatments were synchronized so that $\mathrm{L}_{3}$ was reached at the same time in every treatment.

the $\mathrm{L}_{3}$, and therefore the treatment used different setup times. In order for maternal age effects not to influence the worms, all treatments were set up with different mothers for the different treatments, always of the same age (two days of adulthood, during peak reproduction). To setup the treatments, three plates were prepared for each strain and temperature combination, with 20 unique mature adults ovipositing for $2 \mathrm{~h}$ at $20^{\circ} \mathrm{C}$. Once the synchronized ovipositions were terminated, adults were removed and the plates with the eggs were divided equally among three temperature treatments: $15^{\circ} \mathrm{C}, 20^{\circ} \mathrm{C}$ and $25^{\circ} \mathrm{C}$. Eggs were allowed to hatch and develop in the assigned temperature treatments until the achievement of $\mathrm{L}_{3}$ stage (i.e. at $72,42,32 \mathrm{~h}$ of age for $15^{\circ} \mathrm{C}, 20^{\circ} \mathrm{C}$ and $25^{\circ} \mathrm{C}$, respectively). When $\mathrm{L}_{3}$ was reached, 60 worms per treatment per strain $(\mathrm{N}=360)$ were placed into individual $35 \mathrm{~mm}$ petri dishes and moved back to $20^{\circ} \mathrm{C}$. Consequently, size, growth rate, total reproduction and fitness were measured. Forty worms per strain per treatment were photographed every $24 \mathrm{~h}$ for 5 consecutive days for growth rate assessment starting from the day when $\mathrm{L}_{3}$ larvae were switched to $20^{\circ} \mathrm{C}$ (this constitutes day 0). Size was measured from photographs as the total area of the worm, using the software Image J (v1.46, 
Schneider et al. 2012). Growth was calculated as the size of the worm each day, divided by the number of days since day 0 . All worms were, every $24 \mathrm{~h}$ checked and, if still alive, moved to a new plate. The old plate was kept in order for eggs to hatch, and offspring were after $48 \mathrm{~h}$ counted for daily fecundity assessment. The experiment was terminated when all worms died.

\section{$\underline{\text { Statistical analyses }}$}

All data were analyzed with $R$ 3.6.1 [39]. Overall body size and growth rate were analyzed with a general linear mixed model approach for repeated measures implemented in the lme4 package [40] including day (which is equivalent to an age counted in days), larval temperature treatment, strain and all two- and three-way interactions as fixed effects. We included worm ID as a random intercept and a random slope effect to account for individual variation in area or growth rate with age. Furthermore, we also included day ${ }^{2}$ as fixed effect and all interactions with day ${ }^{2}$ to account for curvature. We performed AIC model selection with two additional models without the three-way interaction with day ${ }^{2}$ or without any of the three-way interactions, respectively. Significance of fixed parameters were assessed using $\chi^{2}$ tests implemented in the car package [41]. For analyses of growth, we also included size as a covariate, to control for any size-dependency of growth.

Reproduction was analyzed both as total reproduction and as individual fitness $\lambda_{\text {ind }}$, which encompasses the timing of reproduction and is analogous to the intrinsic rate of population growth [42]. As a rate-sensitive measure, $\lambda_{\text {ind }}$ gives increased weight to early reproduction. We calculated $\lambda_{\text {ind }}$ by constructing a population projection matrix for each individual, and then calculated the dominant eigenvalue from this matrix [43]. To synchronize the emergence of our focal individuals as $L_{3}$ 
larvae, we directly manipulated the developmental time by keeping them for different duration in the different temperature treatments. However, since $\lambda_{\text {ind }}$ is sensitive to differences in development time, we set the same development time for all treatments in the projection matrix, so that any divergence in $\lambda_{\text {ind }}$ would reflect the treatment response of the age-specific reproduction, and not the development time differences during the treatment exposure. Both total reproduction and $\lambda_{\text {ind }}$ were investigated with a general linear model approach including larval temperature treatment, strain ( $N 2$ or trpa-1) and their interaction as fixed effects. Finally, we tested lifespan with a Cox proportional hazard regression model (package survival) including larval treatment, strain and their interaction as fixed effects. Worms dying of matricide (internal hatching of eggs) were censored.

Ten individuals remained small throughout the whole experiment, eight of which in the $15^{\circ} \mathrm{C}$ trpa- 1 treatment. As our focus was on growth rate, these individuals were excluded from all analyses.

Since the trpa- 1 worms in $20^{\circ} \mathrm{C}$ showed an aberrant growth pattern, all analyses were performed both with the full dataset and with a reduced dataset, where the $20^{\circ} \mathrm{C}$ treatment was removed for both strains. This was to ensure that the trpa- 1 in $20^{\circ} \mathrm{C}$ was not driving any pattern found.

\section{Results}

We found that both strain and larval temperature treatment affected size, and these factors interacted with day and $\mathrm{day}^{2}$, (Table 1, Figure 2). AIC model selection indicated 
Table 1. Size. The effect of juvenile temperature treatment $\left(15^{\circ} \mathrm{C}, 20^{\circ} \mathrm{C}\right.$ and $\left.25^{\circ} \mathrm{C}\right)$, strain (wild-type, trpa-1), day, day ${ }^{2}$ and their interactions on the daily size (measured as area). This final model was obtained by model simplification using AIC.

\begin{tabular}{|c|c|c|c|}
\hline Parameter & $\chi^{2}$ & d.f. & $\mathbf{p}$ \\
\hline (Intercept) & 477.16 & 1 & $<0.001$ \\
\hline Treatment & 57.32 & 2 & $<0.001$ \\
\hline Strain & 4.25 & 1 & 0.039 \\
\hline Day & 3500.34 & 1 & $<0.001$ \\
\hline Day $^{2}$ & 2110.56 & 1 & $<0.001$ \\
\hline Treatment $\times$ Strain & 40.01 & 2 & $<0.001$ \\
\hline Treatment $\times$ Day & 7.58 & 2 & 0.023 \\
\hline Strain $\times$ Day & 7.40 & 1 & 0.007 \\
\hline Treatment $\times$ Day $^{2}$ & 13.07 & 2 & 0.001 \\
\hline Strain $\times$ Day $^{2}$ & 18.46 & 1 & $<0.001$ \\
\hline
\end{tabular}

that the best model for body size increase was the one without any of the three-way interactions (Supplementary Table 1). Body size increased significantly with day, but treatment effects differed between the strains. In the wild-type, the $15^{\circ} \mathrm{C}$ treatment worms rapidly increased in size (showed compensatory growth) and the $25^{\circ} \mathrm{C}$ treatment worms grew smallest, but there was no effect of treatment in the trpa-1 mutant worms. After switching to $20^{\circ} \mathrm{C}$, wild-type worms from the $15^{\circ} \mathrm{C}$ treatment fully compensated 
A

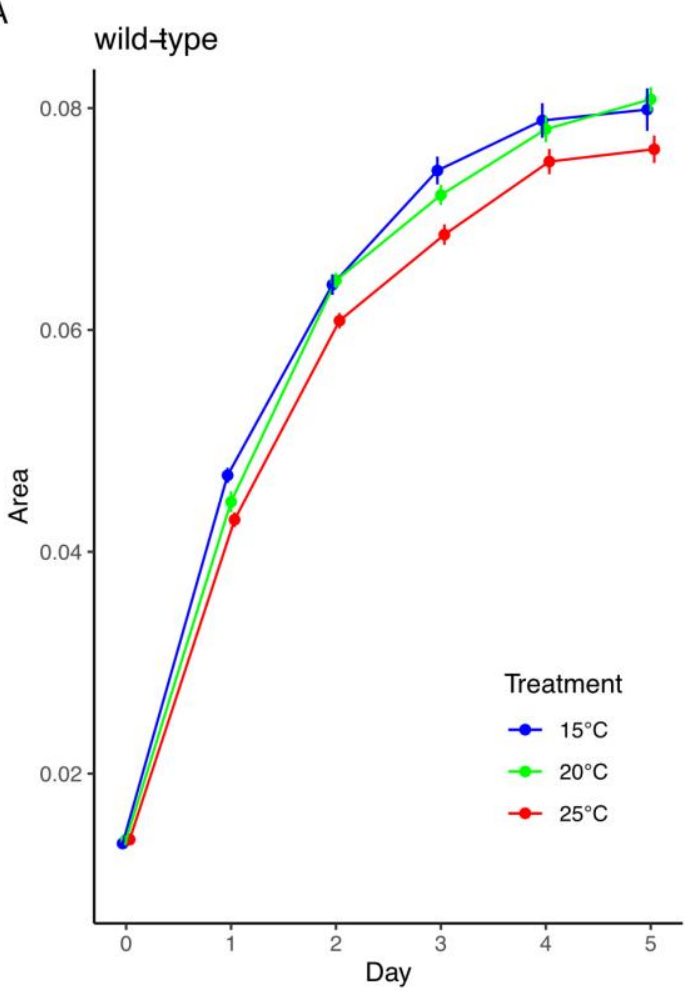

B

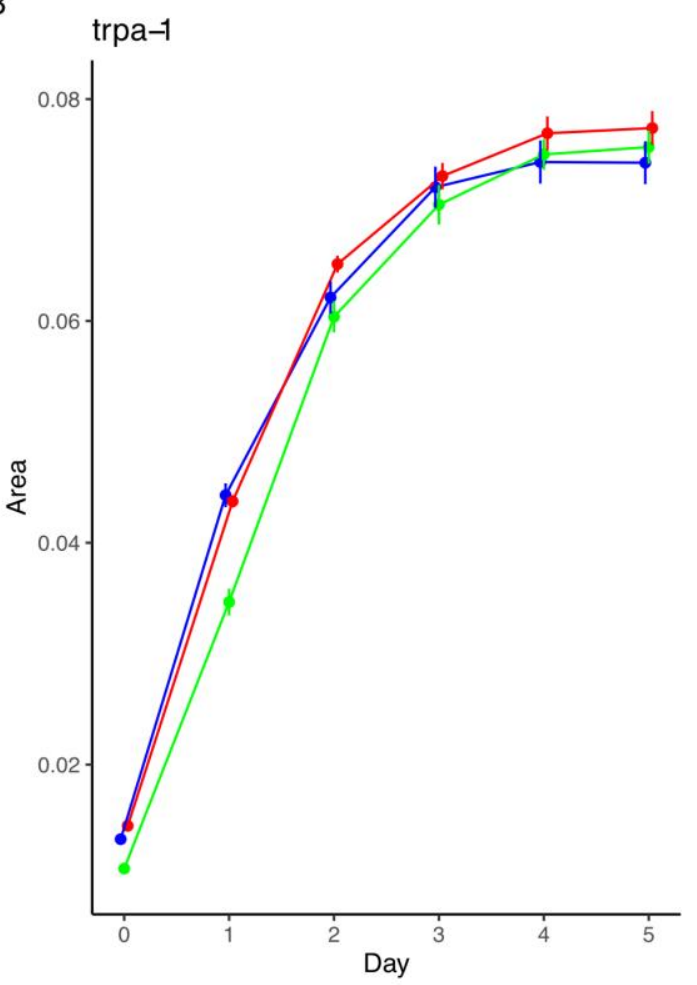

Figure 2. Variation in body size measured as body area in $\mathrm{mm}^{2}$ for (A) wild-type and (B) trpa-1 mutant worms. Day 0 is the day on which the switch to $20^{\circ} \mathrm{C}$ was performed, corresponding to the molt from $\mathrm{L}_{2}$ to $\mathrm{L}_{3}$. In blue, green and red are displayed $15^{\circ} \mathrm{C}, 20^{\circ} \mathrm{C}$ and $25^{\circ} \mathrm{C}$ larval treatments respectively. Symbols represent mean $\pm \mathrm{SE}$.

and reached the same final size as the worms from the $20^{\circ} \mathrm{C}$ treatment, while worms from the $25^{\circ} \mathrm{C}$ larval treatment never reached the size of individuals from the $20^{\circ} \mathrm{C}$ treatment. However, the trpa-1 mutant worms from the $20^{\circ} \mathrm{C}$ treatment showed a very small size at $\mathrm{L}_{3}$ and thus differed strongly from the $20^{\circ} \mathrm{C}$ wild-type treatment worms. To ensure that the interaction between strain and treatment was not driven by the trpa- 1 and $20^{\circ} \mathrm{C}$ combination, we also performed this and all other analyses of all traits both with and without the $20^{\circ} \mathrm{C}$ treatment (for both strains). When removing the $20^{\circ} \mathrm{C}$ treatment from the models, we still found a strong interaction between strain and treatment, reinforcing our interpretation of compensatory growth only being present in the wild-type (Supplementary Table 1-3). 
For growth rate, AIC model selection showed that the best model included also the three-way interactions with day and day ${ }^{2}$ (Table 2). Growth rate decreased with age showing a strong interaction between strain and treatment, both in the full dataset (Table 2) and when the $20^{\circ} \mathrm{C}$ treatment was removed (Supplementary Table 2). In the wild-type strain, the $15^{\circ} \mathrm{C}$ treatment individuals, which had delayed juvenile development, expressed compensatory growth during the first day after switching to the standard $20^{\circ} \mathrm{C}$ temperature, and later showed a similar daily growth to the $20^{\circ} \mathrm{C}$ treatment worms but always higher than the $25^{\circ} \mathrm{C}$ treatment individuals (Figure 3). In contrast, the $15^{\circ} \mathrm{C}$ treatment worms did not show compensatory growth in the trpa- 1 mutant strain. The trpa- 1 mutant worms from the $20^{\circ} \mathrm{C}$ treatment showed very low initial growth, but the significant Treatment $\times$ Strain interaction was still present after removing the $20^{\circ} \mathrm{C}$ treatments (Supplementary Table 2), confirming that the two strains have different compensatory growth responses after being delayed by suboptimal juvenile conditions.

Reproduction was analyzed both as individual fitness $\lambda_{\text {ind }}$ and total reproduction. For individual fitness $\lambda_{\text {ind, }}$ which emphasizes early reproduction, we found a significant interaction between strain and treatment (Table 3, Figure 4A). While individual fitness was generally higher in wild-type worms, the ordering of the treatment differed in the two strains, where a beneficial effect of larval exposure to $15^{\circ} \mathrm{C}$ found in wild-type worms were not present in trpa-1 mutants. Total reproduction was also higher in wild-type worms but the beneficial effect on individual fitness of larval exposure to $15^{\circ} \mathrm{C}$ found for wild-type worms was not present in total reproduction (Table 3, Figure 4B). In trpa-1 mutants, total reproduction was lowest for worms that developed at $15^{\circ} \mathrm{C}$. 
Table 2. Growth rate. The effect of juvenile temperature treatment $\left(15^{\circ} \mathrm{C}, 20^{\circ} \mathrm{C}\right.$ and $\left.25^{\circ} \mathrm{C}\right)$, strain (wild-type, trpa-1), day, day ${ }^{2}$ and their interactions on the daily growth rate, with Size included as a covariate to control for size-specific growth rate.

\begin{tabular}{|c|c|c|c|}
\hline Parameter & $\chi^{2}$ & d.f. & $\mathbf{p}$ \\
\hline (Intercept) & $1.10 \mathrm{E}+05$ & 1 & $<0.001$ \\
\hline Treatment & $1.85 \mathrm{E}+02$ & 2 & $<0.001$ \\
\hline Strain & $4.12 \mathrm{E}+00$ & 1 & 0.042 \\
\hline Day & $3.45 \mathrm{E}+03$ & 1 & $<0.001$ \\
\hline Day $^{2}$ & $7.04 \mathrm{E}+02$ & 1 & $<0.001$ \\
\hline Size & $1.57 \mathrm{E}+04$ & 1 & $<0.001$ \\
\hline Treatment $\times$ Strain & $8.85 \mathrm{E}+01$ & 2 & $<0.001$ \\
\hline Treatment $\times$ Day & $1.94 \mathrm{E}+02$ & 2 & $<0.001$ \\
\hline Strain $\times$ Day & $1.88 \mathrm{E}+00$ & 1 & 0.170 \\
\hline Treatment $\times$ Day $^{2}$ & $1.42 \mathrm{E}+02$ & 2 & $<0.001$ \\
\hline Strain $\times$ Day $^{2}$ & $1.23 \mathrm{E}-01$ & 1 & 0.726 \\
\hline Treatment $\times$ Strain $\times$ Day & $8.93 \mathrm{E}+01$ & 2 & $<0.001$ \\
\hline Treatment $\times$ Strain $\times$ Day $^{2}$ & $6.07 \mathrm{E}+01$ & 2 & $<0.001$ \\
\hline
\end{tabular}


A

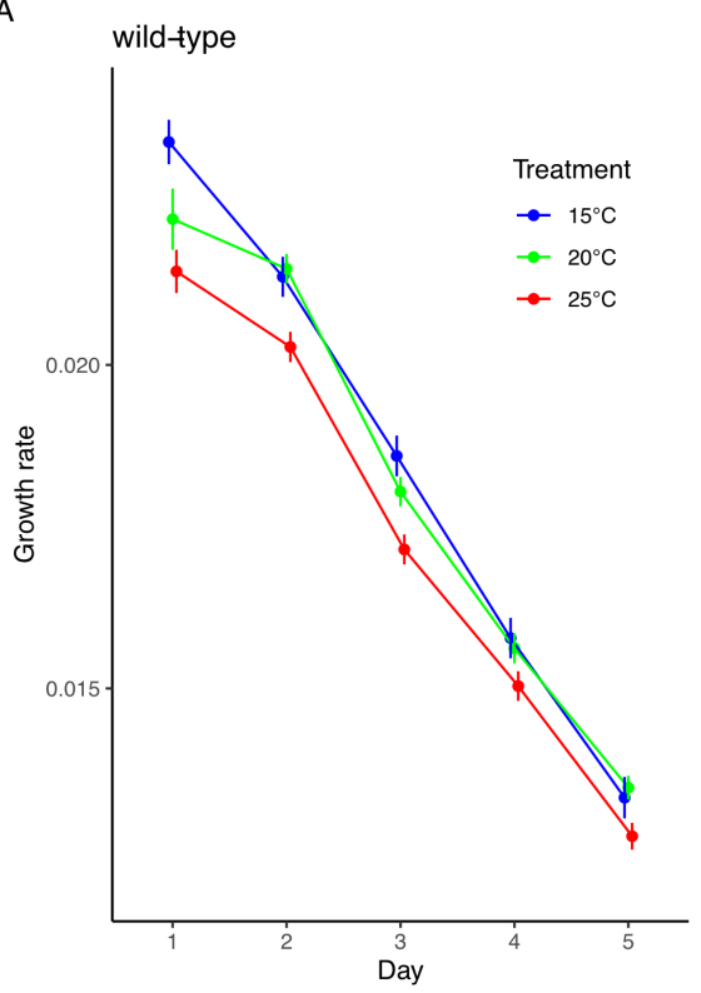

B

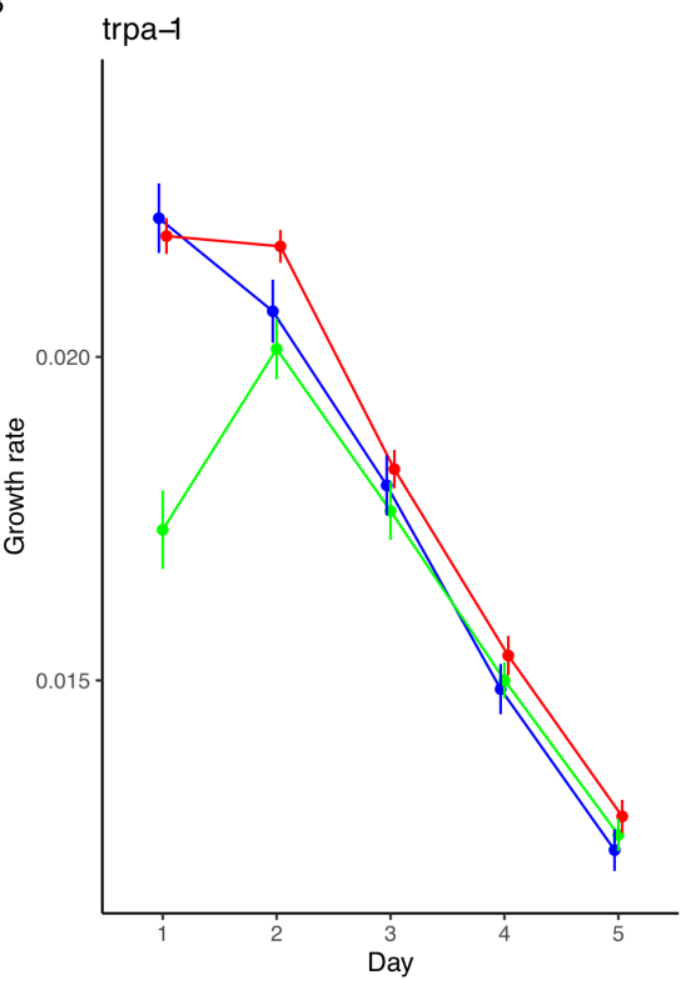

Figure 3. Daily growth rate since the end of temperature switch at day 0, for (A) wild-type and (B) trpa- 1 mutant worms. In blue, green and red are displayed $15^{\circ} \mathrm{C}, 20^{\circ} \mathrm{C}$ and $25^{\circ} \mathrm{C}$ larval treatments, respectively. Symbols represent mean \pm SE.

Table 3. Individual fitness and total reproduction. The effect of juvenile temperature treatment $\left(15^{\circ} \mathrm{C}, 20^{\circ} \mathrm{C}\right.$ and $\left.25^{\circ} \mathrm{C}\right)$, strain (wild-type, trpa-1), and their interactions on individual fitness and total reproduction.

\section{Individual \\ fitness}

\begin{tabular}{lcccccccccc} 
Parameter & d.f. & SS & MS & F & $\mathbf{p}$ & d.f. & SS & MS & F & p \\
\hline Treatment & 2 & 0.67 & 0.33 & 4.93 & 0.008 & 2 & 15482 & 7741 & 1.77 & 0.172 \\
Strain & 1 & 3.62 & 3.62 & 53.56 & $<0.001$ & 1 & 96345 & 96345 & 21.99 & $<0.001$ \\
$\begin{array}{l}\text { Treatment } \\
\text { Strain }\end{array}$ & 2 & 1.01 & 0.51 & 7.49 & 0.001 & 2 & 43151 & 21575 & 4.92 & 0.008 \\
Residuals & 338 & 22.84 & 0.07 & & & 338 & 1480776 & 4381 & &
\end{tabular}


A

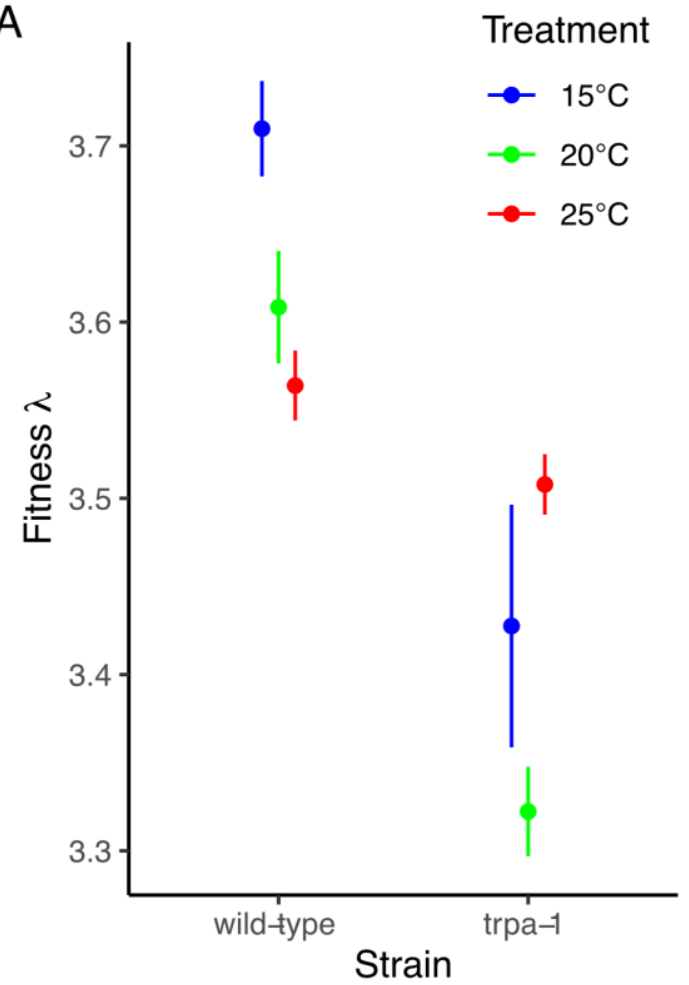

B

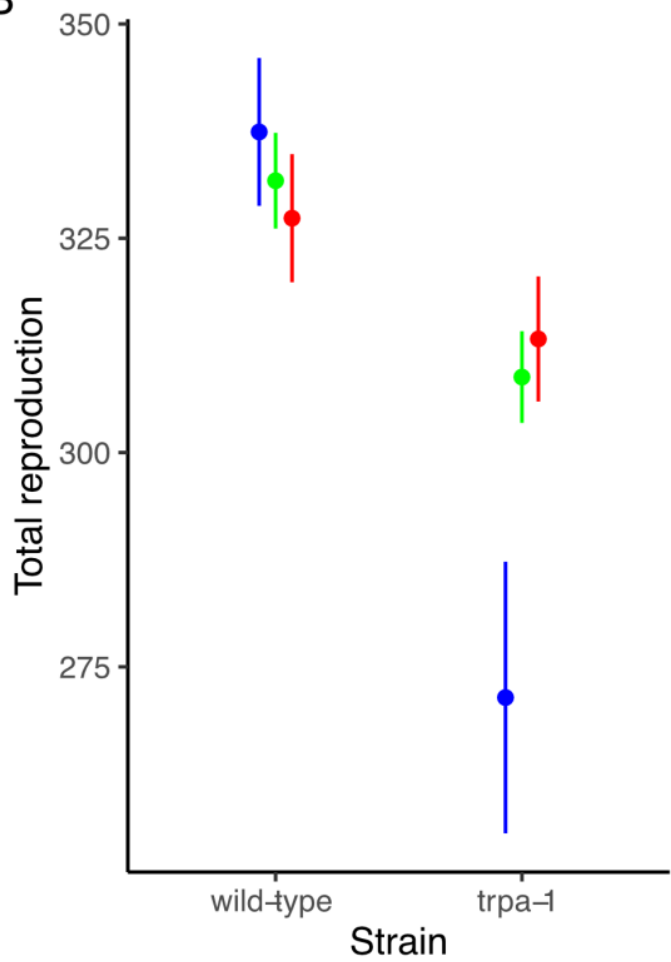

Figure 4. (A) Individual fitness $\lambda_{\text {ind }}$ and (B) total reproduction for wild-type and trpa- 1 mutant worms. In blue, green and red are displayed $15^{\circ} \mathrm{C}, 20^{\circ} \mathrm{C}$ and $25^{\circ} \mathrm{C}$ larval treatments, respectively. Symbols represent mean \pm SE.

Again, removing the $20^{\circ} \mathrm{C}$ treatment did not alter the main findings for individual fitness or total reproduction (Supplementary Table 3). The age-specific reproduction curves show that, for wild-type worms, the $15^{\circ} \mathrm{C}$ juvenile treatment causes high reproduction during the first three days, but a fast decline thereafter, contributing to the high individual fitness (Figure 5A) without affecting the total reproduction. In contrast, for trpa-1 worms, the $15^{\circ} \mathrm{C}$ juvenile treatment leads to low daily reproduction, except for the first day, and the $20^{\circ} \mathrm{C}$ treatment stands out with individuals that show a delayed reproductive schedule contributing to their low individual fitness (Figure 5B). Despite the presence of compensatory growth in wildtype worms, we did not find any lifespan cost (Figure 6). 
A

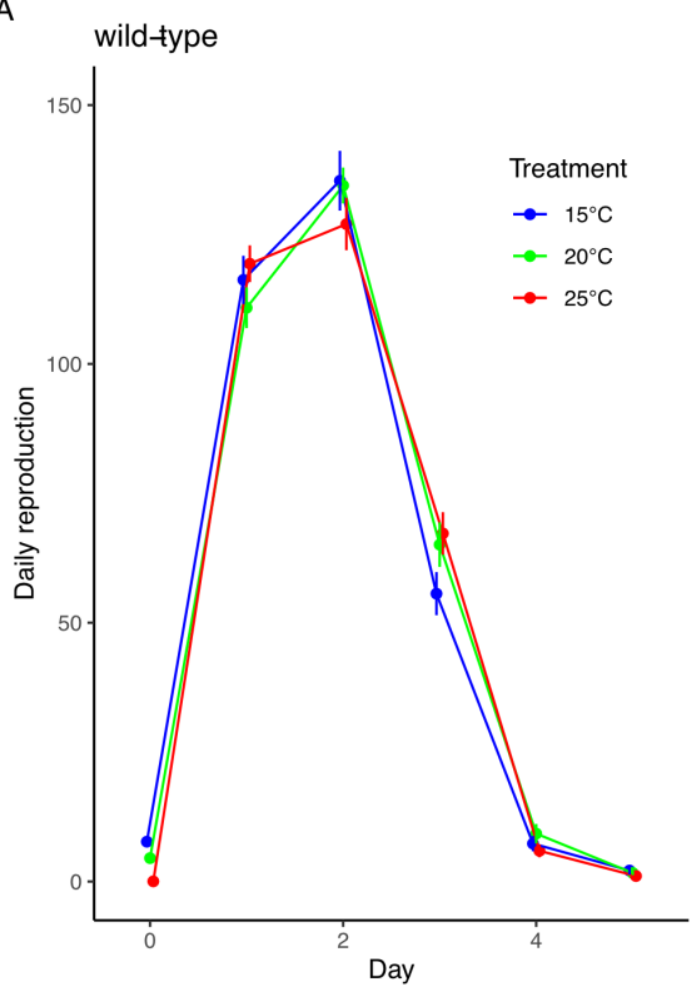

B

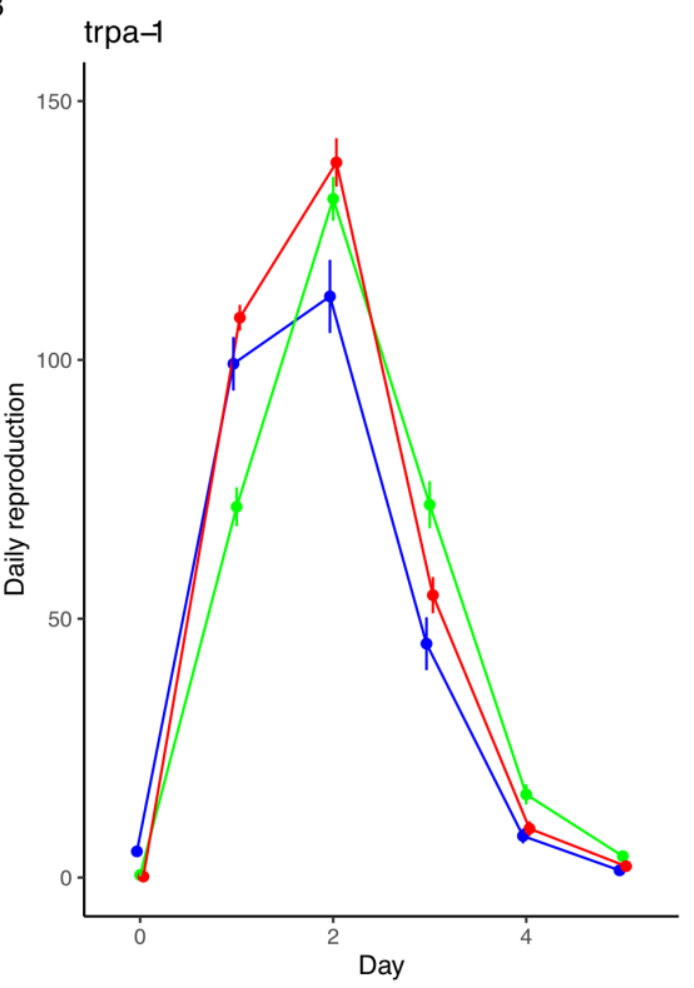

Figure 5. Daily reproduction for (A) wild type and (B) trpa-1 mutant worms. In blue, green and red are displayed $15^{\circ} \mathrm{C}, 20^{\circ} \mathrm{C}$ and $25^{\circ} \mathrm{C}$ larval treatments, respectively. Symbols represent mean $\pm \mathrm{SE}$.

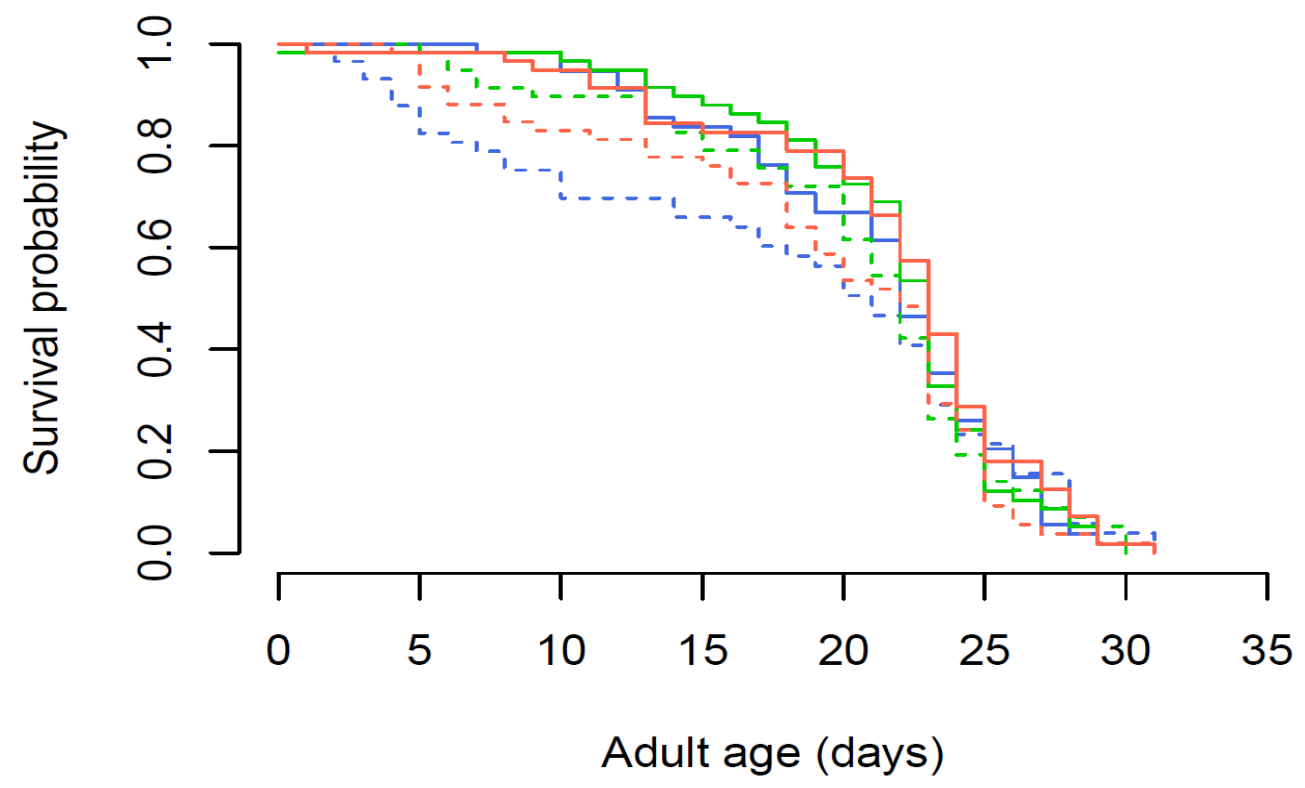

Figure 6. Adult lifespan, starting from the day of molting from $\mathrm{L}_{2}$ to $\mathrm{L}_{3}$. Solid and dotted lines indicate wild-type and trpa- 1 mutants respectively, while blue, green and red indicate $15^{\circ} \mathrm{C}, 20^{\circ} \mathrm{C}$ and $25^{\circ} \mathrm{C}$ larval treatments, respectively. 


\section{Discussion}

We found that $C$. elegans nematodes express compensatory growth as a response to unfavorable juvenile conditions. In particular, cold-exposed wild-type worms compensate for larval cold exposure by reaching the final adult size faster, and by starting reproduction earlier. Not only did cold-exposed $w t$ worms engage in a faster (or anticipated) growth and reproductive schedule once conditions returned favorable, but they also had higher individual fitness with no apparent cost on lifespan. In contrast, trpa-1 mutants with a knock-out of the gene involved in cold-sensitive TRPA-1 channel did not increase growth after unfavorable larval conditions, and correspondingly did not increase fitness either. We show that compensation for a bad start takes place with no life-history costs within-generation, and that compensatory growth in response to low juvenile temperature is regulated by the gene trpa-1, which in turn is a key regulator of daf-16 in the IIS pathway [35].

We found that compensatory growth plasticity is present in wild-type $C$. elegans nematodes, since they respond to unfavorable juvenile temperatures by increasing their growth rate above that of worms growing up at optimal temperature conditions. While compensatory growth is found across several taxa such as insects [44], mammals [8], amphibians [9], birds [12] and fish [13-16], it is not always present, and can instead be seen as a strategy that is adaptive mainly in timeconstrained and seasonal environments, or when large size is under strong selection. For example, compensatory growth is present in amphibians from time-constrained northern latitudes, but not in southern populations $[9,17]$. Similarly, sticklebacks from ponds that are selected for large size show compensatory growth, but the smaller marine sticklebacks do not [14]. Since Caenorhabditis nematodes have reduced female reproduction if adult body size is pharmacologically reduced [45], and the 
natural habitat of $C$. elegans is ephemeral with rapidly decaying plant material [46] creating strong time-constraints, compensatory growth is, therefore, predicted to be adaptive under natural settings.

While compensatory growth is common across taxa, its molecular regulation remains unknown. Here, we show that compensatory growth in response to low juvenile temperature is regulated by the thermo-sensitive TRPA-1 ion channel in $C$. elegans. While wild-type worms respond to low juvenile temperature with compensatory growth once returned to favorable temperature, the trpa-1 knockout mutants do not increase their growth rate. Furthermore, they also do not show any fitness response to temperature treatment, in contrast to the wild-type individuals. This constitutes, to our knowledge, the first example of a gene regulating compensatory growth plasticity. TRPA-1 ion channel acts as an upstream regulator of DAF-16 in the insulin-like signaling (IIS) pathway [34,35]. As the only FOXO homolog in C. elegans, DAF-16 integrates upstream signaling and directs multiple responses in life-history and physiology, such as development, stress resistance and ageing, and DAF-16/FOXO is conserved from worms to mammals (reviewed in [47]). Moreover, since the IIS pathway integrates multiple environmental cues [26-28] and induces plastic responses across organisms [29-31] it has been suggested as a master regulator for adaptive phenotypic plasticity [25]. Our finding that TRPA-1, which integrates into the IIS pathway, regulates compensatory growth plasticity in response to temperature in C. elegans reinforces this view.

Surprisingly, we found no life-history cost of compensatory growth, neither in reproductive fitness nor in lifespan. For reproduction, we instead found that worms experiencing compensatory growth had a higher reproductive fitness $\lambda_{\text {ind, }}$ caused by an earlier reproductive peak, but not higher total reproduction. Our finding that the 
total reproduction was unaffected by the knockout of trap-1 mirrors the previous findings of Zhang et al. [35]. However, we further show that an effect can be found, when a rate-sensitive fitness measure $\left(\lambda_{\text {ind }}\right)$, which gives higher weight to early reproduction, is used. In a growing population, $\lambda_{\text {ind }}$ is considered the best fitness measure, since reproducing early will increase the number of future descendants $[42,43]$. Since the natural habitat of $C$. elegans is decaying plant matter, populations show a rapid boom and burst reproductive strategy [48], and thus, the importance of early reproduction is eminent. While reproductive consequences of compensatory growth are seldom measured, the few studies with such data have mixed findings. For instance, Dmitriew and Rowe [44] detected no reproductive consequences in ladybird beetles, while Auer et al. [3] found that female guppies experiencing compensatory growth had lower offspring production. It can be argued that the ultimate reason to express compensatory growth is to restore fitness and, thus, a reproductive fitness cost is not to be predicted, but a positive effect on reproductive fitness, as we found, is not expected. Interestingly, the fitness increase is caused by an earlier timing of reproduction, which is a direct consequence of the compensatory growth. Thus, future studies should focus not only on viable offspring number but also integrate the timing of reproduction into a rate-sensitive measure such as individual fitness [42]. It should be, however, noted that similarly to previous studies we did not measure offspring quality, but only the number of offspring that survived for at least 48 hours (i.e. until the reproduction measurement was taken). The potential trade-off between number and quality of offspring is well known in the life history literature [49,50], and such inter-generational trade-offs have recently been found in Caenorhabditis nematodes [51] but are not ubiquitous [52]. 
While reproductive consequences of compensatory growth are under-studied, its consequences for lifespan have been in greater focus. A number of studies now provide evidence for lifespan costs across taxa [13,53], even if costs in lifespan are sometimes only present under certain environmental conditions [44]. In this study, we did not detect any costs in terms of lifespan, and we were, thus, unable to replicate the findings of Zhang et al. [35], who found that cold-exposure during the juvenile period shortens lifespan in wild-type but not in trpa-1 mutants. A possible explanation for the difference between the studies might be the use of the antibiotic kanamycin, which was used to fight bacterial infections and which was not used by Zhang et al. [35]. Kanamycin may potentially interact with the temperature treatment and affect the lifespan of worms. The two studies have relatively similar sample sizes per treatment, with 30 reproducing worms in Zhang et al. [35] and 60 in the present work. Other possible costs of compensatory growth may not involve life-history traits, but can be detrimental for the organism under challenging natural conditions, such as impaired cognitive performance [12], reduced immune-response [10] or higher antioxidant activities [11].

To conclude, we find that $C$. elegans express compensatory growth in response to suboptimal juvenile temperature, and that the cold-sensitive TRP ion channel TRPA-1, which is an upstream regulator of the IIS signaling pathway, regulates this response. These findings open up for future studies of an ecologically relevant and widespread form of phenotypic plasticity using the powerful C. elegans model system and the associated phenotypic and molecular tools. 


\section{Acknowledgements}

We thank Andrea Hinas for aid with experimental design. This work was supported by the Swedish Research Council VR Grant 2016- 05195 and the Carl Tryggers Stiftelse grant CTS 17: 285 to M.I.L.

\section{References}

1. Dewitt TJ, Scheiner SM. 2004 Phenotypic plasticity: Functional and conceptual approaches. American Journal of Human Biology (doi:10.1002/ajhb.20088)

2. Metcalfe NB, Monaghan P. 2001 Compensation for a bad start: grow now, pay later? Trends in Ecology \& Evolution 16, 254-260. (doi:10.1016/S01695347(01)02124-3)

3. Auer SK, Arendt JD, Chandramouli R, Reznick DN. 2010 Juvenile compensatory growth has negative consequences for reproduction in Trinidadian guppies (Poecilia reticulata). Ecology Letters 13, 998-1007. (doi:10.1111/j.14610248.2010.01491.x)

4. Chown SL, Gaston KJ. 1997 The species-body size distribution: energy, fitness and optimality. Functional Ecology 11, 365-375. (doi:10.1046/j.13652435.1997.00096.x)

5. Dmitriew CM. 2011 The evolution of growth trajectories: what limits growth rate? Biological Reviews 86, 97-116. (doi:10.1111/j.1469-185X.2010.00136.x)

6. Jobbling M. 2010 Are compensatory growth and catch-up growth two sides of the same coin. Aquac. Int. 18, 501-510. (doi:10.1007/s10499-009-9260-8) 
7. Hector KL, Nakagawa S. 2012 Quantitative analysis of compensatory and catchup growth in diverse taxa. The Journal of Animal Ecology 81, 583-593. (doi:10.1111/j.1365-2656.2011.01942.x)

8. Ozanne SE, Hales CN. 2004 Catch-up growth and obesity in male mice. Nature 427, 411-412. (doi:10.1038/427411b)

9. Orizaola G, Dahl E, Laurila A. 2014 Compensatory growth strategies are affected by the strength of environmental time constraints in anuran larvae. Oecologia 174, 131-137. (doi:10.1007/s00442-013-2754-0)

10. Murillo-Rincón AP, Laurila A, Orizaola G. 2017 Compensating for delayed hatching reduces offspring immune response and increases life-history costs. Oikos 126, 565-571. (doi:10.1111/oik.04014)

11. Burraco P, Valdés AE, Orizaola G. 2020 Metabolic costs of altered growth trajectories across life transitions in amphibians. The Journal of Animal Ecology 89, 855-866. (doi:10.1111/1365-2656.13138)

12. Fisher MO, Nager RG, Monaghan P. 2006 Compensatory Growth Impairs Adult Cognitive Performance. PLoS Biology 4, e251.

(doi:10.1371/journal.pbio.0040251)

13. Lee W-S, Monaghan P, Metcalfe NB. 2013 Experimental demonstration of the growth rate-lifespan trade-off. Proceedings of the Royal Society B: Biological Sciences 280, 20122370-20122370. (doi:10.1098/rspb.2012.2370)

14. Ab Ghani NI, Merilä J. 2015 Population divergence in compensatory growth responses and their costs in sticklebacks. Ecol Evol 5, 7-23. (doi:10.1002/ece3.1342) 
15. Royle NJ, Lindström J, Metcalfe NB. 2006 Effect of growth compensation on subsequent physical fitness in green swordtails Xiphophorus helleri. Biology Letters 2, 39-42. (doi:10.1098/rsbl.2005.0414)

16. Morgan IJ, Metcalfe NB. 2001 Deferred costs of compensatory growth after autumnal food shortage in juvenile salmon. Proceedings of the Royal Society of London. Series B: Biological Sciences 268, 295-301. (doi:10.1098/rspb.2000.1365)

17. Dahl E, Orizaola G, Nicieza AG, Laurila A. 2012 Time constraints and flexibility of growth strategies: geographic variation in catch-up growth responses in amphibian larvae. Journal of Animal Ecology 81, 1233-1243. (doi:10.1111/j.1365-2656.2012.02009.x)

18. Metcalfe NB, Monaghan P. 2003 Growth versus lifespan: perspectives from evolutionary ecology. Experimental Gerontology 38, 935-940. (doi:10.1016/S0531-5565(03)00159-1)

19. Dmitriew C, Rowe L. 2011 The effects of larval nutrition on reproductive performance in a food-limited adult environment. PLoS One 6. (doi:10.1371/journal.pone.0017399)

20. Fontana L, Partridge L, Longo VD. 2010 Dietary restriction, growth factors and aging: from yeast to humans. Science 328, 321-326. (doi:10.1126/science.1172539)

21. Flatt T, Heyland A. 2011 Mechanisms of life history evolution. Oxford University Press. See https://oxford.universitypressscholarship.com/view/10.1093/acprof:oso/97801995 68765.001.0001/acprof-9780199568765-chapter-1. 
22. Dantzer B, Swanson EM. 2012 Mediation of vertebrate life histories via insulinlike growth factor-1. Biological Reviews 87, 414-429. (doi:10.1111/j.1469185X.2011.00204.X)

23. Lind MI, Chen H-Y, Cortazar-Chinarro M, Maklakov AA. 2017 Rapamycin additively extends lifespan in short- and long-lived lines of the nematode Caenorhabditis remanei. Experimental Gerontology 90, 79-82. (doi:10.1016/j.exger.2017.01.017)

24. Durmaz E, Rajpurohit S, Betancourt N, Fabian DK, Kapun M, Schmidt P, Flatt T. 2019 A clinal polymorphism in the insulin signaling transcription factor foxo contributes to life-history adaptation in Drosophila. Evolution 73, 1774-1792. (doi:10.1111/evo.13759)

25. Regan JC, Froy H, Walling CA, Moatt JP, Nussey DH. 2019 Dietary restriction and insulin-like signalling pathways as adaptive plasticity: A synthesis and reevaluation. Functional Ecology 34, 107-128. (doi:10.1111/1365-2435.13418)

26. Metaxakis A, Tain LS, Grönke S, Hendrich O, Hinze Y, Birras U, Partridge L. 2014 Lowered insulin signalling ameliorates age-related sleep fragmentation in Drosophila. PLOS Biology 12, e1001824. (doi:10.1371/journal.pbio.1001824)

27. Sim C, Kang DS, Kim S, Bai X, Denlinger DL. 2015 Identification of FOXO targets that generate diverse features of the diapause phenotype in the mosquito Culex pipiens. Proc Natl Acad Sci U S A 112, 3811-3816. (doi:10.1073/pnas.1502751112)

28. Feeney KA et al. 2016 Daily magnesium fluxes regulate cellular timekeeping and energy balance. Nature 532, 375-379. (doi:10.1038/nature17407)

29. Mortzfeld BM, Taubenheim J, Klimovich AV, Fraune S, Rosenstiel P, Bosch TCG. 2019 Temperature and insulin signaling regulate body size in hydra by the 
Wnt and TGF-beta pathways. Nature Communications 10, 3257.

(doi:10.1038/s41467-019-11136-6)

30. Snell-Rood EC, Moczek AP. 2012 Insulin signaling as a mechanism underlying developmental plasticity: the role of FOXO in a nutritional polyphenism. PLOS ONE 7, e34857. (doi:10.1371/journal.pone.0034857)

31. Green DA, Extavour CG. 2014 Insulin signalling underlies both plasticity and divergence of a reproductive trait in Drosophila. Proc Biol Sci 281. (doi:10.1098/rspb.2013.2673)

32. Nicieza AG, Metcalfe NB. 1997 Growth compensation in juvenile atlantic salmon: responses to depressed temperature and food availability. Ecology 78, 2385-2400. (doi:10.2307/2265901)

33. Álvarez D, Nicieza AG. 2002 Effects of temperature and food quality on anuran larval growth and metamorphosis. Functional Ecology 16, 640-648. (doi:10.1046/j.1365-2435.2002.00658.x)

34. Xiao R, Zhang B, Dong Y, Gong J, Xu T, Liu J, Xu XZS. 2013 A genetic program promotes $C$. elegans longevity at cold temperatures via a thermosensitive TRP channel. Cell 152, 806-817. (doi:10.1016/j.cell.2013.01.020)

35. Zhang B, Xiao R, Ronan EA, He Y, Hsu A-L, Liu J, Xu XZS. 2015 Environmental temperature differentially modulates $C$. elegans longevity through a thermosensitive TRP channel. Cell Reports 11, 1414-1424. (doi:10.1016/j.celrep.2015.04.066)

36. Kindt KS, Viswanath V, Macpherson L, Quast K, Hu H, Patapoutian A, Schafer WR. 2007 Caenorhabditis elegans TRPA-1 functions in mechanosensation. Nat. Neurosci. 10, 568-577. (doi:10.1038/nn1886) 
37. Lionaki E, Tavernarakis N. 2013 High-throughput and longitudinal analysis of aging and senescent decline in Caenorhabditis elegans. Methods in Molecular Biology (Clifton, N.J.) 965, 485-500. (doi:10.1007/978-1-62703-239-1_32)

38. Schneider CA, Rasband WS, Eliceiri KW. 2012 NIH Image to ImageJ: 25 years of image analysis. Nat Methods 9, 671-675. (doi:10.1038/nmeth.2089)

39. R Core Team. 2018 R: A language and environment for statistical computing.

40. Bates D, Mächler M, Bolker B, Walker S. 2015 Fitting linear mixed-effects models Using Ime4. Journal of Statistical Software 67, 1-48. (doi:10.18637/jss.v067.i01)

41. Fox J, Weisberg S. 2010 An R companion to applied regression. Second edition. Thousand Oaks CA: Sage Publications.

42. Brommer JE, Merilä J, Kokko H. 2002 Reproductive timing and individual fitness. Ecology Letters 5, 802-810.

43. McGraw JB, Caswell H. 1996 Estimation of individual fitness from life-history data. The American Naturalist 147, 47-64.

44. Dmitriew C, Rowe L. 2007 Effects of early resource limitation and compensatory growth on lifetime fitness in the ladybird beetle (Harmonia axyridis). Journal of Evolutionary Biology 20, 1298-1310. (doi:10.1111/j.1420-9101.2007.01349.x)

45. Lind MI, Zwoinska MK, Meurling S, Carlsson H, Maklakov AA. 2016 Sexspecific tradeoffs with growth and fitness following life-span extension by rapamycin in an outcrossing nematode, Caenorhabditis remanei. The Journals of Gerontology Series A: Biological Sciences and Medical Sciences 71, 882-890. (doi:10.1093/gerona/glv174)

46. Félix M-A, Braendle C. 2010 The natural history of Caenorhabditis elegans. Curr. Biol. 20, R965-969. (doi:10.1016/j.cub.2010.09.050) 
47. Zečić A, Braeckman BP. 2020 DAF-16/FoxO in Caenorhabditis elegans and its role in metabolic remodeling. Cells 9. (doi:10.3390/cells9010109)

48. Frézal L, Félix M-A. 2015 C. elegans outside the Petri dish. eLife 4. (doi:10.7554/eLife.05849)

49. Stearns SC. 1992 The Evolution of Life Histories. Oxford University Press.

50. Roff D, editor. 1993 The evolution of life histories: theory and analysis. Springer US. See https://www.springer.com/gp/book/9780412023910.

51. Mautz BS, Lind MI, Maklakov AA. 2020 Dietary restriction improves fitness of aging parents but reduces fitness of their offspring in nematodes. J Gerontol A Biol Sci Med Sci 75, 843-848. (doi:10.1093/gerona/glz276)

52. Lind MI, Ravindran S, Sekajova Z, Carlsson H, Hinas A, Maklakov AA. 2019 Experimentally reduced insulin/IGF-1 signaling in adulthood extends lifespan of parents and improves Darwinian fitness of their offspring. Evol Lett 3, 207-216. (doi:10.1002/evl3.108)

53. Inness CLW, Metcalfe NB. 2008 The impact of dietary restriction, intermittent feeding and compensatory growth on reproductive investment and lifespan in a short-lived fish. Proc Biol Sci 275, 1703-1708. (doi:10.1098/rspb.2008.0357) 